\title{
Road User Charging for Urban Freight Vehicles: A Systems Approach
}

\author{
Loshaka Perera, Russell G. Thompson \\ Department of Infrastructure Engineering, University of Melbourne, Melbourne, Australia \\ Email: perera.loshaka@gmail.com
}

How to cite this paper: Perera, L. and Thompson, R.G. (2020) Road User Charging for Urban Freight Vehicles: A Systems Approach. Journal of Transportation Technologies, 10, 214-243.

https://doi.org/10.4236/jtts.2020.103014

Received: April 16, 2020

Accepted: May 28, 2020

Published: June 1, 2020

Copyright $\odot 2020$ by author(s) and Scientific Research Publishing Inc. This work is licensed under the Creative Commons Attribution International License (CC BY 4.0).

http://creativecommons.org/licenses/by/4.0/

(c) (i) Open Access

\begin{abstract}
Road user charging (RUC) has a long history as a mechanism to recover infrastructure maintenance and capital costs. The present RUC systems are facing issues such as transparency, cross-subsidization, environmental concerns and reducing revenue due to the likes of lessening fuel tax as vehicles become more efficient. Therefore, this paper reviews the strengths and weaknesses of the present RUC mechanisms implemented in the world with respect to stakeholder problems and demands of the freight industry and to describe the need for a more appropriate, practical and sustainable approach that can be used in the future. Finally, a model is proposed that is transparent and considers usage-based charging addressing most of the weaknesses highlighted in the models reviewed. Further, it considers externalities produced by heavy vehicles into account. The model has the potential to provide answers to key stakeholder issues and will lead to a sustainable freight transport system in the future. Encouraging fuel-efficient modes, optimization of loading, routing and logistics systems, and long term land use planning are a few of them.
\end{abstract}

\section{Keywords}

Road User Charge, Heavy Vehicles, Externalities, City Logistics, Systems Approach

\section{Introduction}

Road user charging (RUC) was first introduced in a form of fuel tax to recover infrastructure maintenance and capital cost. In the past, tracking every vehicle to charge for road usage was infeasible due to technical and administrative difficulties and thus taxing fuel was introduced as an indirect method of charging since fuel being a good supplementary product associated with vehicle usage. With technological advancements and evolvements in road user behavior, more charges 
such as registration fees, many forms of license fees and toll charges were introduced reforming road user charges. More details about the evolution of road user charging and tools are discussed later in this paper.

RUC system is faced with multiple problems in today's context. The two key stakeholders in this context are road authorities and users, faced with two major problems. Authorities demand more revenue since present and future earnings from existing RUC are not sufficient to cover the cost of infrastructure (including maintenance) while users debate that the present system is unfair because the link between usage and charging is weak, thus lead to cross-subsidization. Residents, being another powerful stakeholder in today's context, demand detailed consideration of environmental and social factors such as noise, air quality and road safety.

Road user charges often focus on heavy vehicles (significant numbers are freight) since they occupy more road space and do the greatest damage to the road network. At the same time, freight movement is an important sector in any society or economy. As a result, the present RUC system plays a vital role in shaping freight transportation in the world.

Sustainable freight transportation demands not only economic optimization but also consideration of safety, environmental and social impacts, un-interrupted quality of service and energy efficiency. Stakeholders have enormous demands and expectations and thus solutions need to look at multi-objective multi-stakeholder structures. Monopolistic approaches that are in use only consider commercial gains and no longer acceptable. Thus, an integrated approach involving the likes of City Logistics is overdue.

This paper identifies key stakeholders, their problems and demands with respect to RUC and reflects on major charging schemes implemented around the world. Finally, a new road charging model is proposed that addresses major issues and problems highlighted in the review.

\section{Common Schemes Used for Road User Charging}

Fuel taxes, permit and registration fees have traditionally been collected to recover infrastructure use costs [1]-[8] and tolls were charged for various purposes. Fuel taxation started in the 1920s and remains in operation for some countries (including Australia) to recover road usage costs. This tax was initially introduced as a method to recover user costs since it's very easy to collect and theoretically fuel is a good supplementary product to measure vehicle usage. Thus, fuel consumption was a relatively equitable measure to distribute system costs [1] [9].

In other words, the more distance you travel or the more weight you carry, the amount of fuel burnt is proportional and as a result, fuel tax is a good indirect way of charging for road usage. These assumptions are now questionable due to development of more fuel-efficient vehicles, larger truck combinations, progressive penetration of alternative fuels, and thus fuel tax has become an unreliable 
mechanism to charge for road usage [3] [9] [10] [11]. On the other hand, kilometers driven per liter has gone up (more efficient engines) over time but the cost of maintenance never decreased (rather gone up) and as a result, revenue collected through fuel tax has become insufficient to cover road costs [3] [12] [13] [14]. Furthermore, when fuel prices drop, the amount of tax collected may decrease if the tax is a fixed percentage of the selling price, e.g. in Australia where tax is a fixed percentage (25\%) over cost [15]. Thus, revenue cannot be estimated and major deficit occurs over time [16]. During recession times a reduction in Vehicle Miles Travelled (VMT) leads to less fuel consumption, generating less tax revenue than expected. As a result of the aforementioned reasons fuel tax is not sufficient enough to support capital and maintenance costs and found to be an outdated method as a tool to charge users. This situation was also in the US and many other countries but they have reformed to use non-fuel based sources of financing that cater to evolving customer demands [3] [17] [18].

The following reasons were highlighted by [19] as to why fuel-based tax is outdated and in-efficient in his study. Heavy vehicles damage the roads more severely but do not pay in the right proportion to this damage and sometimes the jurisdiction of fuel purchase and the site of actual travel is not the same. For example, international hauliers in Europe and interstate hauliers in the US always pump fuel from a cheap point and travel via countries or states. The motor fuel tax does not give vehicle operators an indication or information regarding the total cost of a particular trip, such as one in congested traffic conditions, may impose on society. It is not practical for government agencies to provide incentives with fuel taxes to vehicle operators to change the nature of their road use, including loading pattern, travel on high standard roads where damage from HV could be minimum or shifting to off-peak hours.

Other than fuel tax, registration charges are another popular charge imposed by authorities around the world mostly without any rigorous rationality. The mere elements considered in determining such charge is a fixed element of infrastructure cost, administration cost and emission level in some countries. As a result, placing greater emphasis on vehicle registration fees is not a good strategy since these fees have a very weak relationship to the amount of road usage by individuals in today's context and thus the charges are inexplicit [9].

Tolling is a financial charge imposed over road users either to raise finance (recover cost of infrastructure) or to control their usage or to change their behavior. Toll charges may be used to recover capital investment (spent on infrastructure development) or as a traffic management tool if variable pricing is adopted based on demand. Beyond the usual framework, toll being charged in some countries to control emission in cities. At present, it's popular among many countries to charge tolls on their roadways to finance new infrastructure. The use of Public-Private-Partnership (PPP) for new infrastructure development is rising, particularly in Europe, Latin America and Australia [20]. The popularity of Pub- 
lic-Private-Partnership (PPP) is growing in the world due to many reasons. Rapid growth in public demand over more infrastructure and constraints on public budgets have hard-pressed the authorities to look for alternative financing options, creating the demand for such investments, while clear terms of returns stipulated in PPP contracts have attracted the private market [21] [22] balancing the supply side. The latest trend in toll roads is to charge heavily on heavy vehicles [10] [23].

In 1975 Singapore introduced an area-based pricing scheme [24] as a congestion management tool for the first time in the world [25]. Charges were imposed to control the number of vehicles entering city limits and charges vary by time of a day. Many cities introduced congestion pricing to manage traffic at city limits since then. Apart from Singapore, London (UK), some metropolitan areas in the USA, and Stockholm (Sweden) are major success stories in congestion charging in the world. Transport researches have carried out much research to find out optimum toll charge for congestion control with different parameters [26]-[33]. In the year 2008, Milan (Italy) introduced a slightly different urban pricing scheme which was to curb the pollution in the city of Milan [34]. Charges are based on the Euro emission standard of the vehicle entering the city and have achieved its objectives successfully.

Usually, public acceptability of toll charges is very low but this attitude could be positively changed if road users achieved improved roads based on the monies collected. When setting up toll prices, states may have a genuine interest in maximizing throughput as well as maximizing revenue, but these two are inherently conflicting with each other and impossible to satisfy simultaneously [35]. From the public point of view toll affordability, congestion management, income maximization/subsidy minimization aspects are carefully considered before accepting such a policy [35]. More aspects of acceptability are discussed later in this paper under constraints.

\section{Review of Existing RUC Schemes Using a Systems Approach}

City logistics is defined as, "the process for totally optimizing the logistics and transport activities by private companies with the support of advanced information systems in urban areas considering the traffic environment, the traffic congestion, the traffic safety and the energy savings within the framework of a market economy" [36].

"City logistics is based on system approach which promotes innovative schemes that reduce the total cost, including economic, social, and environmental cost of goods movement within cities" [37]. The systems approach [38] divides a larger problem into pieces and arrives at a solution systematically. Therefore, this approach is used to solve many problems in the freight industry and to provide more sustainable solutions. Thus, a systems approach is used in this study to review road user charging systematically and to propose a valid solution. 
The rest of the paper is organized as follows. First, it identifies the stakeholders in the freight industry, their problems, goals and objectives associated with RUC. Section 3 reviews several major RUC systems implemented in the world using major components of systems approach. Section 4 introduces a model, its appropriateness, objectives and future directions. Section 5 concludes the study.

\subsection{Stakeholders}

Problem definition is the first main step in the systems approach. Since the problem has multi-tiers it is important to identify the multi-stakeholders, their objectives and their problems (Table 1).

\subsection{Existing Schemes}

This section of the paper reviews the major road user charging systems implemented in other countries of the world.

\subsubsection{Road User Charging Schemes in Europe}

In the past, like any other country in the world, Europe is also charged fuel taxes and some fixed taxes to recover expenditure on its highway system [2]. The aim of the introduction of Eurovignette in the EU was to recover construction, maintenance, repair and environmental costs on their road network. More importantly, ensuring unbiased competition and stopping discrimination among hauliers in the member states. However, this was a time-based charging system that is jointly operated by Belgium, Denmark, Luxemburg, the Netherlands and Sweden [39]. The main problem found with the Eurovignette system was the charges do not consider the distance travels by a vehicle, but the time, and therefore poorly correlated with infrastructure costs. On the other hand, distance-based tolls found to be corresponding much more closely to the cost of infrastructure use [40].

Table 1. Stakeholders and their problems, goals, objectives.

\begin{tabular}{|c|c|c|}
\hline Stakeholders & Problems & Goals/Objectives \\
\hline $\begin{array}{l}\text { Government/ } \\
\text { Administers }\end{array}$ & $\begin{array}{l}\text { Insufficient revenue, users demand } \\
\text { better solutions, users hesitant to } \\
\text { pay taxes, delays, congestion, } \\
\text { crashes, pollution, energy-inefficient } \\
\text { modes of transport }\end{array}$ & $\begin{array}{l}\text { Revenue for infrastructures } \\
\text { maintenance and to build new ones, } \\
\text { safety and livable cities, efficient and } \\
\text { sustainable mode of transport, } \\
\text { energy-saving, economic development }\end{array}$ \\
\hline Carriers & $\begin{array}{l}\text { Operational cost, RUC, } \\
\text { infrastructure, travel time, receiver } \\
\text { demands }\end{array}$ & $\begin{array}{l}\text { Cost minimization, efficient } \\
\text { transportation, safety }\end{array}$ \\
\hline Shippers/Receivers & $\begin{array}{l}\text { Carrier charges, reliability, quality of } \\
\text { transport, delivery times, delivery } \\
\text { frequency, stock management }\end{array}$ & $\begin{array}{l}\text { On-time deliveries, cost minimization, } \\
\text { fewer stock-outs, }\end{array}$ \\
\hline Residents & $\begin{array}{l}\text { Crashes, congestion, noise, } \\
\text { emissions, land use, modes of } \\
\text { transport, TOD travel, }\end{array}$ & $\begin{array}{l}\text { Quality air, less noise, safety, aesthetic } \\
\text { appearance, efficient transportation, } \\
\text { livable cities }\end{array}$ \\
\hline $\begin{array}{l}\text { Private Investors } \\
\text { (road infrastructure) }\end{array}$ & Demand \& toll charge & Return on investment \& safety \\
\hline
\end{tabular}


Later they changed to "polluter pays" principle from the "user pays" principle to allow for the internalization of the external costs. Many countries came up with their charging mechanisms considering different aspects. According [3], in Europe, road generated revenues exceed road expenditures in all the countries studied. This means road charges have subsidized other policies. To understand the basic principles few major policies in Europe are first reviewed here.

\section{1) German heavy goods vehicles charging system}

Heavy good vehicles over 12 tonnes on German motorways have to pay a distance-based charge since 2005, January [40] [41]. This charge was imposed on top of existing taxes and hauliers have continuously argued that the charge was too high.

The German HGV tolling scheme is aimed at goods vehicles over the gross vehicle weight of 12 tonnes to recover the full cost. This includes all costs of construction, maintenance and operation of motorways and also charging scheme operating cost. The charge level is determined based on vehicle characteristics such as weight, number of axles, and the emission class [10]. The introduction of this charging scheme in Germany in 2005, known as LKW-Maut, resulted in a large number of heavy vehicles avoiding tolls by means of diverting from Western Germany to France where the main highways are not tolled yet [5].

The latest advanced technology is used for the German HGV charging scheme. Satellite positioning and mobile telephone communication technology cover all the required aspects of such a charging system. A mobile telephone connection was made between the vehicle on-board unit (OBU), which combines a GPS receiver and a digital map and charging centre. This acts as the transponder for the charging scheme.

\section{2) UK Lorry charging scheme}

The British government had planned to introduce a lorry road user charge system (LRUC) in 2008 but was abandoned the introduction in the year 2005 [5] [40]. The charges would have applied to all trucks over the gross weight of 3.5 tonnes, over the entire road network and offer the varying charges by the time of day, road type and zone. The reason for withdrawal was the complexity of the proposed project and the government decided to introduce a simple distance-based user charge system. A device called tachograph was installed to all heavy vehicles over 3.5 tonnes, operating within the EU, to measure the distance. This installation was compulsory and distance travelled during each year was observed at the point of registration and tolls are calculated accordingly. The British government did not charge for the mileage run in other countries by vehicles registered in the UK but engaged in international haulage. A fuel rebate was given based on a benchmarked fuel efficiency level to omit double taxation. This benchmarked system has certainly penalized vehicles underperforming in terms of efficiency and encouraged vehicles with high fuel efficiencies [5]. This toll charging system was purely focused on charging a fair share for using the UK roads by overseas hauliers rather than generating additional revenue for transport investments [40]. 


\subsubsection{Swiss and Austrian Heavy Vehicles Tolling Systems}

Since 1985 flat fee for Heavy Goods Vehicles (HGV) was in existence and it was changed to a nationwide distant related fee, named as the LSVA, since Swiss government predicts a $100 \%$ increase in HGV on the Swiss road network as a result of bilateral treaties made with the European Union to extend the maximum weight limit of HV from 28 tons to 34 tons, and to 40 tons later on. After a referendum and a subsequent vote, the LSVA started on January $1^{\text {st }} 2001$.

The LSVA applies to all domestic and foreign heavy vehicles transporting either goods or passengers with a maximum laden vehicle weight of over 3.5 tons. For domestic vehicles installation of an On-Board-Unit (OBU) was mandatory. Foreign vehicles are predominantly using a ticket fetched at self-service machines. The distances travelled by each HGV, on all public roads (not only motorways) in the country are measured using the tachograph. A tachograph is switched on and off when crossing the border. Charges are calculated based on the distance travelled maximum permissible vehicle weight and emission class of the vehicle [42].

Trucks and buses on Austrian roadways were subjected to a time-based toll system until 2004, where distance-based pricing was introduced [43]. In Austria, there's an OBU called "Go Box" and all trucks over 3.5 tonnes of gross weight are mandatory to fix an OBU. Light vehicles still have to pay the time-related user fee based on Vignette. Gross weight and axle configuration (3 classes) are considered when determining road user charges per kilometer travelled, but not emission parameters unlike in Switzerland. Only motorways and express roads are subjected to toll, as a result, diversion of traffic to local and regional parallel roads was inevitable. However, the proportions are found to be insignificant (less than $2 \%$ of the total traffic on motorways).

\subsubsection{Heavy Vehicle Charging in the US}

In the United States, highway users pay for their roadway use through indirect user fees that are levied at the federal, state, and local levels. Federally, the primary sources of truck user fee revenues are fuel taxes. Other federal truck user fees include sales taxes on trucks, tractors, trailers, and tires, and an annual fixed-rate heavy vehicle use tax (HVUT) [3]. These tax rates vary depending on gross vehicle weight (GVW). Other than that weight-distance tax (WDT), overweight and over-dimension permit fees try to recover some components of the road damages in some states.

The revenue generated primarily through fuel taxes found to be insufficient to maintain the federal highway system (public sector subsidizes the road system) and many suggestions were proposed in the past as measures to increase revenue. Increase in fuel taxes, at least to keep pace with inflation, spreading the use of toll highways, imposing new taxes and fees, and encouraging private investments such as PPP's are among them [3] [14] [44].

Vehicle Miles Travelled (VMT) based fee has been identified as the most suitable option in the long run in the US because it could establish a reliable source of funding, reduce traffic congestion, promote more efficient use of vehicles with higher loading capacities, and discourage unladen miles travelled. However, im- 
plementing a usage-based pricing scheme such as VMT based faced several challenges. For example, public and political acceptance, technology, administration and financial feasibility [18] are a few of them which are discussed in detail later in this paper. As a result, fuel taxes still exist in the United States [3].

At present, there are more than 300 toll roads in the USA [45]. Most toll roads define their base toll rate structures according to the vehicle number of axles and some HVs are tolled according to registered GVW. Taken together, the analyses conducted by [45] have strongly concluded that toll policies across the United States have penalized large commercial vehicles disproportionately. In his study, the toll charges were compared for various types of vehicles considering the following parameters. Vehicle lengths, load equivalency factors, consumption of road space and the damage caused to the pavement are such parameters.

Congestion has emerged as one of the greatest challenges faced by transport planners and authorities in developed economies. It's a major social cost to the society and the cost was estimated as high as $\$ 78$ billion in 2005 in the USA and is growing rapidly as a result of speedy increases in travel delays experienced by users every day. The cost was estimated not only in terms of lost time but productivity, air pollution, and energy wasted is considered. As a solution to these severe levels of congestion, the U.S. Department of Transportation has recently started a program to initiate congestion pricing in five metropolitan areas [46].

State Highway Cost Allocation Studies (HCAS) have a long history in the United States spanning over 70 years. More than 80 studies have been performed in at least 30 states during that time [47]. Federal Highway Cost Allocation Studies (HCAS) was completed and concluded in 1997 in the United States [48] and no major changes have occurred since then. According to [18], this self-financing scheme was designed to attain maximum efficiency followed by horizontal equity. This comprehensive usage-based charging system will enable self-finance construction, operation, and maintenance cost of the highway system and calculates user fees based on vehicle class, weight, configuration and distance travel on each facility. However, externalities produced by vehicles are not considered in this user charging scheme such as congestion and emissions and thus authors have stated that future studies need to introduce such cost components into the scheme [18] [48]. In the year 2000, HCAS was revised to reflect social costs calculated by the Environmental Protection Agency (EPA) in the US. As a result, crash, congestion, air pollution and noise costs were introduced and user fee based on vehicles type and environment condition (urban/rural) was re-calculated [49]. However, any of these HCAS were not fully implemented in United States mainly due to political setting that focuses on painless revenue generation from established sources rather than instigating equity among highway user classes [47].

\subsubsection{Heavy Vehicle Charging Schemes in Australia}

Heavy vehicles (any vehicle or trailer with a mass over 4.5 tonnes) in Australia are subjected to two pricing charges. Namely; a road user charge (RUC) and an annual registration fee. The RUC is a levy on each liter of diesel an HV consume and presently it's about 38.14 cents per liter. The National Transport Commis- 
sions (NTC) provides recommendations for setting these heavy vehicle charges which are based on a charging framework known as pay-as-you-go (PAYGO). This was introduced in Australia in 1992 [15] [50].

The PAYGO system tries to recover the road usage cost from each heavy vehicle type and to recover a share of common road costs, such as street lighting, rest bays and signage. PAYGO scheme follows a simple mechanism to calculate heavy vehicle charges using the latest heavy vehicle and trailer population data available at NTC. They have considered seven-year averages for both road expenditure and vehicle usage data assuming that charges do not change significantly in response to short-term changes in expenditure or vehicle use [16] [50].

In Australia, revenue recovered through heavy vehicle charges helps the government to provide better and safer roads. According to NTC, around 40 percent of heavy vehicle costs are recovered as state and territory registration fees, with the balance paid through a fuel-based road user charge which is collected by the Commonwealth Government [50].

In Australia approximately three-fourths of the HV fleet is owned by ancillaries and rest is by for-hire. It is obvious that for-hire use more road kilometers than ancillaries and registration cost is determined based on a cost-recovery scheme which considers historic expenditure on-road services. Therefore, the registration fee determined for vehicle type irrespective of its ownership or real usage leads to very high inaccuracy. In addition, there are substantial variations in registration costs between states in Australia for no valid reason. Therefore, cross-subsidization is very high in Australia.

As mentioned before, Australia became commonplace for PPP and has a growing number of toll roads in main cities and claim to be the country having the largest (in terms of lane kilometers) urban tolled road network in the world [20]. Based on the study carried out by [51] it was found that freight movements in the Melbourne metropolitan region is higher than interstate freight in Australia, which explains why toll roads with PPP are popular in cities of Australia. In general, toll charges in Australia are based on the distance of travel, vehicle type (very broad classification) and Time of Day. However, toll charges vary over facilities and sections with in the same facility as highlighted by [52] [53] in their studies. Australia firstly introduced the ETC system in the CityLink project for toll collection [54]. Despite the availability of the latest technology in CityLink appropriateness of toll charges (representing true user charge) stipulated in CityLink road is deplorable. As a result, a noteworthy social dialog has begun among the truck community and stakeholders recently in Australia [55].

\subsection{Evaluation}

Evaluation within the systems approach to city logistics is defined as "evaluation involves the methodical comparison of the predicted consequences of schemes, based on a set of predetermined criteria" [56]. A critical evaluation of the key schemes reviewed above was done using an objective-based procedure consid- 
ering a broad range of stakeholders. For more information, refer to [57]. Even though multi-criterion evaluation technique requires derivation of relative weightings, this study has done a qualitative analysis identifying the strengths and weaknesses of each scheme with respect to multi-objective listed under stakeholders, refer Table 2. Because the intended purpose of this evaluation here is to look at how well each scheme has served multi-objectives by stakeholders.

\subsection{Criteria}

The performance of the RUC scheme can be measured using the following criteria.

The total cost of transportation (system equilibrium);

Percentage of usage-based charges;

Transparency.

Table 2. Strengths and weaknesses of emerging user charging approaches.

\begin{tabular}{|c|c|c|}
\hline Scheme & Strengths & Weaknesses \\
\hline \multirow[t]{7}{*}{ German } & ${ }^{\star}$ Cost fully recovered & ${ }^{\star}$ High toll charges \\
\hline & ${ }^{\star}$ Emission considered-encourage efficiency & ${ }^{\star}$ Not on all roads (toll avoidance) \\
\hline & ${ }^{*}$ Technology used & ${ }^{\star} \mathrm{LGV}$ is not charged \\
\hline & ${ }^{\star}$ Eliminated cross-subsidization (foreign hauliers) & ${ }^{\star}$ Noise issue not considered \\
\hline & ${ }^{*}$ Most factors that contribute to usage been used to determine the charge & ${ }^{*} \mathrm{TDM}$ is not considered \\
\hline & & ${ }^{\star}$ Fuel tax \\
\hline & & ${ }^{\star} \mathrm{HV}$ over 12 tonnes are considered \\
\hline \multirow[t]{5}{*}{ UK } & ${ }^{\star}$ Fuel rebate & ${ }^{\star}$ Distance-based cost, not perfect \\
\hline & ${ }^{\star}$ Encourage fuel efficiency of vehicles & ${ }^{\star}$ Externalities are not considered \\
\hline & ${ }^{\star}$ Partially direct method & ${ }^{\star} \mathrm{TDM}$ is not considered \\
\hline & ${ }^{*}$ All roads are tolled & \\
\hline & ${ }^{\star}$ No additional charges (fair) & \\
\hline \multirow[t]{2}{*}{ Switzerland } & ${ }^{\star}$ All roads are tolled & ${ }^{*} \mathrm{TDM}$ is not considered \\
\hline & ${ }^{\star}$ Partially direct method & ${ }^{\star}$ Fuel tax \\
\hline \multirow[t]{4}{*}{ Austria } & ${ }^{\star}$ Partially direct method & ${ }^{\star}$ Emission not considered \\
\hline & & ${ }^{*} \mathrm{TDM}$ is not considered \\
\hline & & ${ }^{\star}$ Fuel tax \\
\hline & & ${ }^{*}$ Not on all roads (toll avoidance) \\
\hline \multirow[t]{4}{*}{ USA } & ${ }^{\star}$ Partially direct method & ${ }^{\star}$ Fuel tax \\
\hline & ${ }^{*}$ Congestion pricing in some areas & ${ }^{*}$ Not on all roads (toll avoidance) \\
\hline & & ${ }^{\star}$ Cross-subsidisation still exist \\
\hline & & ${ }^{\star}$ Externalities are not considered \\
\hline \multirow[t]{6}{*}{ Australia } & ${ }^{*}$ Simple and conventional method & ${ }^{\star}$ Fuel tax \\
\hline & & ${ }^{*}$ Not linked with direct usage (cross-sub) \\
\hline & & ${ }^{\star}$ Externalities are not considered \\
\hline & & ${ }^{*} \mathrm{TDM}$ is not considered \\
\hline & & ${ }^{*}$ Not on all roads (toll avoidance) \\
\hline & & ${ }^{\star}$ High and non-transparent toll charges \\
\hline
\end{tabular}


The ideal scheme shall minimize the total cost of freight transportation in the network and pays charges only based on usage (no cross-subsidization) with a very clear charging methodology (fully transparent).

\subsection{Constraints}

The major constraints found in implementing any new or reformed road user charging could be political and social acceptance of such system and technology, finance or privacy-related issues. Therefore, the following section of this paper reviews such constraints.

\subsubsection{Political and Social Acceptance}

It is a well-established fact that an introduction of a new tax or toll is not usually welcomed with open arms by the public. As a result, any transportation solution that involves such a levy has a political implication and complicated to choose [58 \& 59]. Usually political and public acceptance is linked together where public opinion is mostly concerned by politicians. As a result, it could be stated that road pricing schemes are politically accepted only if it gets sufficient public support. On the other hand, it has been found that strong political decision is a positive measure of higher public acceptance [59].

Road pricing schemes, known as the first-best solution in theory [60], could be limited to the drawing board unless political and public acceptance is achieved. Even though economists are certain about its intended benefits [61] [62], many past proposals have proven that public and political acceptance is a must for successful implementation of such a scheme regardless of how technically well it sounds or the extent to which socio-economic benefits it could generate [24] [59] [60] [61] [63] [64].

Nevertheless, the most refined and reflective policy design will create some losers and induce opposition. In fact, from past failures, it can be stated that a lack of public acceptance, correlated with political acceptance, has been the most important obstacle to implement road pricing charges. Among many such failures reported in the world, cordon schemes were rejected by public referenda in Edinburg and Manchester [63], combined cordon and zonal scheme for Manhattan stopped by the New York state legislature in 2008 [63] and congestion metering proposal rejected in the city of Cambridge are few of them. According to [65], the Cambridge proposal was considered as a concept in the right place at the wrong time reasoning out the public refusal.

As mentioned above, a systematic economic rationale does not always assure political acceptability [66]. Politicians are always keen to apply known or well-established measures such as fuel taxes and registration fees since these measures are more acceptable than that are less known or unknown ones and generate revenue effortlessly [41]. Studies from Europe have found that the acceptance of tolls by stakeholders is high when it applies to all types of vehicles across all countries in Europe. This indicates that equity is greatly concerned by stakeholders. In conclusion, policymakers should endorse the perception of fair- 
ness into road pricing to gain stakeholders' acceptability [67].

Identification of key stakeholders and their expectations is crucial for the successful implementation of the road pricing scheme. Different stakeholders seem to have various expectations that may not in line with the objectives of the road pricing scheme and thus create a negative voice. But there were many proposals failed in the past with perfect schemes due to poor presentation, unclear objectives or improper timing [65] [68]. As a result, it can be concluded that clear objectives, effective communication and re-investment of revenue are primary to win the majority of the stakeholders. As per the prediction of the approach-avoidance theory, public attitudes were mostly adverse just before the introduction of road charges but this dynamic attitude could be changed with test runs [59].

As explained in cognitive dissonance theory [59] [69] people initially tend to refuse the road pricing scheme if the implementation is doubtful, however, more people react positively if the proposal is known to be implemented anyhow. Therefore, uncertainty among policymakers and politicians about the scheme, usually based on its promised results, may lead to more anxiety when trying to win public acceptance [70]. At the same time, the non-availability of a similar system for comparison or maybe a success story to rely on could reduce the acceptance of such schemes at an introductory level [65]. In summary clearly stated objectives, the process and type of data collection and associated technology, and how the revenue raised from the charge is disbursed and detailed information about implementation costs are critical factors that need to be given careful consideration before announcing a road pricing scheme.

Equity issues make the policy proposal politically weak. Horizontal equity and vertical equity are two dimensions that policymakers work on when distributing revenues generated from road pricing. However, who deserves the benefits is yet a debate according to [71]. It could be those who paid the toll or those who change their trip pattern in response to toll providing better conditions for toll payers. In the early nineties, [62] argued that the "political response will depend on the relative numbers of losers and gainers and the amount of utility lost by those motorists who are priced off". But this has grown to a far more extent over the years where equity is concerned.

Apart from whether the public accepts this proposal or not, it was found that politicians have concerns about technology requirements, costs of technology and administration sometimes. Furthermore, enforcement issues and uncertainty with data collected (privacy issues) makes them more worried before presenting to the public [65].

\subsubsection{Technology, Cost and Privacy of Data}

Supporting technology for effective collection of RUC in terms of tolls is a must to the successful implementation of any RUC scheme. Starting from manual toll collection systems in early days, where toll booths are maintained with human support to collect tolls or with automatic coin machines [72] have transferred to more technical based systems such as video or CCTV cameras based systems 
with the aid of license plate recognition software's and so on. For example, infrared cameras with ANPR technology have been deployed on routes into the Stockholm city centre [73]. Initially, the tolls levels were kept flat due to charging (technical) and administrative difficulties [74] but with the advent of new technology such as automatic vehicle identification (AVI) systems make it feasible to invent sophisticate pricing systems in a user-friendly manner [58].

The present era of this technology is Electronic Road Pricing (ETC) which uses gantries and beyond that satellite-based ETC system [73] are now in place in Germany to charge lorry road users. A mobile telephone or GSM based technology has been discussed for some time, but the idea was rejected majorly due to privacy issues. The next generation of technology for RUC could be GPS (satellite) based charging mechanism where data about many parameters such as time of the day, location (geographical location and corresponding road type in use), speed profile, distance travelled, time held up in congestion can be collected promptly. Once data is ready it's just a matter of time to calculate user charge for each vehicle both in terms of direct and externalities using the available schemes, given suitable schemes are available and imposing them on users.

It is worth mentioning that technology used for road pricing charges has led to several problems in the past at the implementation stage and some schemes were even abandoned as a result. Gaining political and public acceptance in the technology used is yet another hurdle in road pricing schemes. When Cambridge tried to introduce congestion metering, the complexity and acceptability of the technology were perceived as a major disadvantage [65]. A device was introduced to be fitted on each vehicle and there were many negative concerns regarding such installation. Respondents expressed that a scheme with less-advanced technology would be more acceptable in the first instance [65]. Similarly, in Hong Kong, the public was doubt about electronic road pricing technology, which was new, untested in a real situation and more likely to fail [75]. Further, the public was suspicious that the government would use this data to tax drivers callously in the future and thus only a few agreed to have their cars fitted with electronic number plates [75]. Also, some groups in Hong-Kong were opposed to electronic road pricing considering it as being technically unrealistic, ethically suspect, absurdly expensive, and socially divisive [75]. Invasion of privacy is also challenged by the public when this nature of advanced technology is used on roads [25] [75] [76]. Experience from Taiwan shows that initial acceptance of ETC was lower than expected [77]. On the other hand, studies from the UK have shown that this is one of the least concerned items by respondents in the UK [68]. Therefore, it can be concluded that technology and data privacy is decisive to introduce and promote a road pricing scheme and needs to be handled carefully.

[78] studied the acceptability of technology by freight vehicles, especially acceptance of the ETC system. From the study, it was found that freight vehicles do not accept electronic tags compared to private cars due to various reasons. Unawareness was found to be the greatest challenge faced by freight vehicles 
hindering the usage of ITS features. Business attributes and attitudes towards technology were found to be highly correlated with freight carrier willingness to accept technology.

The traditional weigh limit enforcement is by static weighing. Weighbridges, wheel and axle scales are used to measure gross vehicle weight and wheel or axle loads [79]. Fixed or portable, static weighing systems suffer from several limitations. Time taken, staff requirements and practical difficulties to measure each truck on a highway are major issues. With the development of technology high-speed weigh-in-motion (WIM) technology has resolved key issues. A more sophisticated version of WIM sensors is available today in the market which can be fixed to the vehicle and communicate with the central control centre.

Usually, the cost of operation is a major consideration in the implementation of a more equipped, technically advanced system and it was found to be approximately $20 \%$ of the revenue collection based on the literature. However, this was found to not be the case with the Swiss system, being $4 \%$ - 6\% of the revenue which is comparatively very low. Thus, it can be considered as the cost is not a constraint anymore for this nature of the application. Moreover, it's a well-accepted fact that technology is advancing every day and more cost-effective devices are coming into the market.

\section{A Model}

It's a well-known fact that heavy vehicles do the greatest damage to pavements, not passenger vehicles [13] [42] [80]. As many studies have stated [2] [42] [81] [82] pavement damage is a function of many variables such as actual loads, distance travelled, number of axles, axle combination, space between axles, tire type and configuration, suspension type, load distribution among axles, speed and load capacity of the vehicle and pavement type (flexible or rigid). It was found that the relationship between axle loads and pavement damage is exponential [2] [42] [80] [83] [84] which pay more attention to HV.

Even though pavement damage is the most significant and direct user cost that needs to be recovered, proper calculation and apportionment were lacking in all the schemes discussed above. German scheme has considered some of the parameters in their scheme and some basics are considered in the Swiss and Austrian schemes. Yet, a complete scheme was not introduced to assign true pavement damage caused by heavy vehicles.

Social and environmental costs (externalities in terms of crashes, congestion, emission, noise, infrastructure cost) that are generated by motor vehicles, especially HVs are becoming more of a concern for societies today. When the feasibility of projects is evaluated these externalities are now incorporated by way of calculating Social Cost-Benefit Analysis (SCBA) beyond the economic BC ratio [85]. From a societal perspective, all transportation users should pay their full costs including private and social [86]. Therefore, it is fair to charge the total cost from heavy vehicle users where equity is maximized. Social and environ- 
mental costs are not direct costs but are borne by society [4]. [53] [87] have studied the social and environmental costs generated by HV using different types of roads and highlighted its significance. This discussion proves that how sensitive the toll decisions are in terms of total cost and stakeholder objectives.

Only a few schemes have considered emission classes when deciding tolls, namely, German, Swiss and UK schemes. But more parameters need to be incorporated to capture the real effect of externalities. Therefore, a more comprehensive model is required to determine toll levels and how to minimize impacts while providing an efficient service.

Furthermore, it was found that toll charges are determined without any acceptable basis and methodology is not transparent to users. As mentioned earlier there's a trend in the world to charge HV profoundly [10] [23]. The CityLink road in Melbourne is one of the most recent examples of that. [53] has previously discussed (early 2016) that CityLink toll charges are significantly higher and leads to more externalities being produced due to toll avoiding nature of HV. Ignoring this fact, CityLink has increased the toll charges for HGV couple of times (increase is about $2 \%-3 \%$ ) during the year 2016, which makes the conditions awful and now they have increased the toll charges by $125 \%$ in effect from $1^{\text {st }}$ of April 2017 to support new infrastructure development [88]. This has led to a noteworthy social dialog being initiated among the truck community and other stakeholders recently in Australia [55]. Another example supporting the same idea, again from Australia, would be the latest toll increase publicized for $\mathrm{HV}$ in Brisbane on the Clem7, Legacy Way, Go Between Bridge toll roads [89]. A comparison was made with car tolls, which was now 2.65 times for $\mathrm{HV}$ and will reach 3 with the new hike. All these examples highlight the fact that there seems to be no scientific basis or model available for governments to negotiate with toll companies in PPPs or to determine optimal toll for trucks looking at system optimization, which leads to a very inefficient HV transportation system.

It was found that toll avoidance behavior is a common issue around the world [40] [43] [53] [90] and excessive toll charges aggravate such avoidance. With logistics sprawl, as studied by [91], demand for faster routes will grow in the future. As a result, the number of heavy vehicles avoiding toll roads in the future will be higher in the absence of proper toll charges. Toll avoidance leads to severe equity issues and cross-subsidization of road users. The condition found to be truly unfair for people who are not using the un-priced road network and substantial advantage for HV using the road heavily every day for zero charges [92]. Therefore, it can be proven that direct road user charges are more appropriate and essential to be applied to all roads before differentiating any freeways or infrastructure that has been developed under private investment schemes. This was well understood by countries like Switzerland, the UK and New Zealand where the entire road network has been tolled [40] [93]. Toll avoidance is not limited to an equity issue or cross-subsidization. It also produces more externalities, high maintenance costs on alternative roads and results in less sustainable transportation systems [43] [53] [87]. 
Therefore, from the literature, it is quite evident that a comprehensive model to charge road users, especially for heavy vehicles is overdue. The following section describes an approach to develop a model.

\subsection{Appropriate Methodology}

Future transport and financial policy objectives require a comprehensive design of pricing schemes to jointly address the efficient and equitable use of road networks, manage congestion, and account for externalities and financing of new infrastructure. New technologies can help imposing variable charges on different classes of users, vehicles and roads considering the level of congestion. Therefore, the demand and capacity utilization can be managed through behavioral responses to pricing and improve network performance as stated by [94]. The ideal road pricing scheme should be dynamic [45] and may consist of a number of sub-models that cumulatively produce a coherent road user charging system for the future. A model should address the objectives of multi-stakeholders including managing congestion. Thus, proposed sub-models are described in Section 4.2 below.

\subsection{Freight Vehicle Cost Model}

As discussed in the previous section this section discusses the development of freight cost model which can be used by planners, especially in Australia.

\subsubsection{Crash Costs}

Crash costs (Accident costs) are calculated as an exposure function considering past data in Victoria, Australia. Thus, it's a function of many vehicles in each class on different road types as mathematically constructed below.

$$
A C_{a}^{m}=f\left(x_{a}^{m}\right) \quad \forall a \in A \cup \bar{A}, m \in M
$$

The flowchart in Figure 1 depicts the crash cost calculation process and Table 3 depicts the final figures applicable for Australia. Since crash data, vehicle kilometers traveled and injury cost data are available in Victoria, Australia the method was successfully adopted to calculate crash costs.

Therefore, the total crash cost can be calculated as:

$$
\sum_{a} \sum_{m} A C_{a}^{m} x_{a}^{m} d_{a} \quad \forall a \in A, m \in M
$$

\subsubsection{Congestion Costs}

Congestion costs $(\mathrm{A} \$ / \mathrm{km})$ are a function of the $\mathrm{v} / \mathrm{c}$ ratio and class-specific vehicle volumes, $x_{a}^{m}$.

$$
C C_{a}^{m}=f\left(x_{a}^{m}, x_{a} / C_{a}\right) \quad \forall a \in A \bigcup \bar{A}, m \in M
$$

The total congestion costs can be calculated as:

$$
\sum_{a} \sum_{m} C C_{a}^{m} x_{a}^{m} d_{a} \quad \forall a \in A, m \in M
$$

The relevant cost figures are extracted from literature and given in Appendix A. 


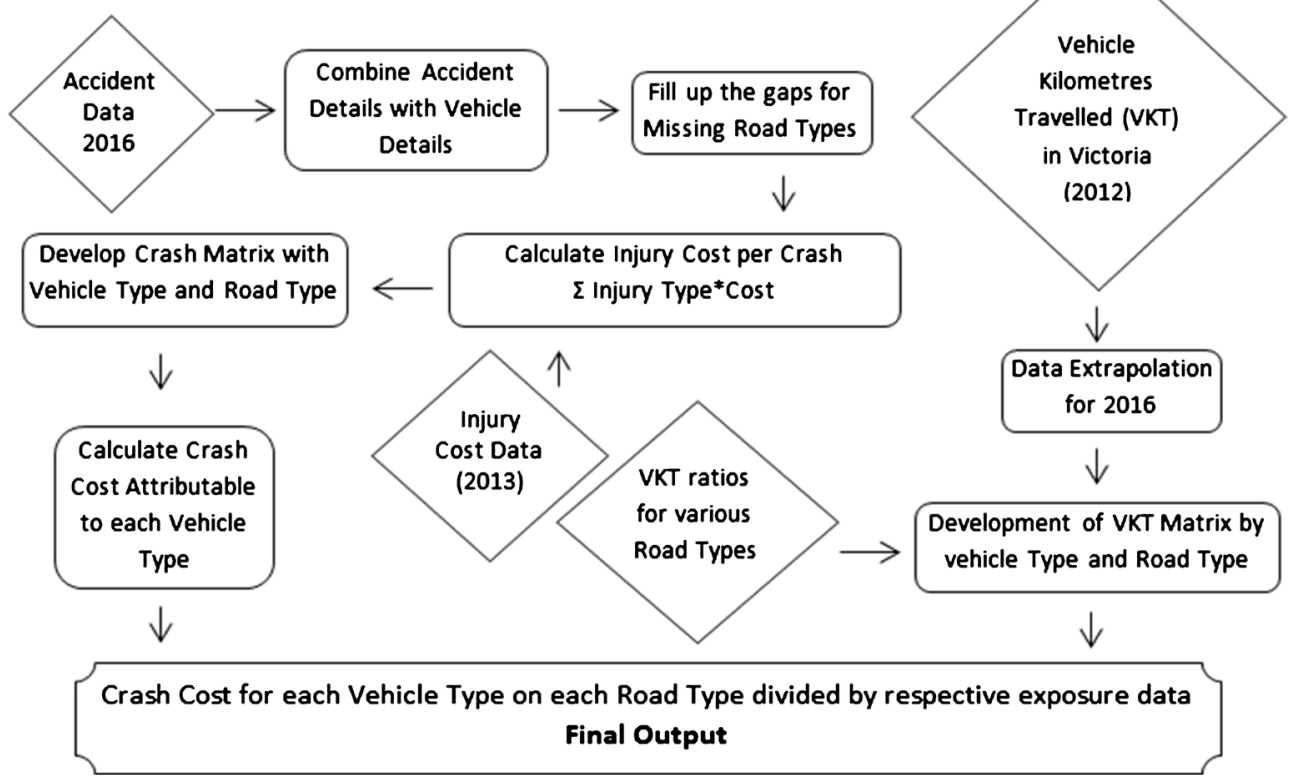

Figure 1. Crash cost calculation process using victorian data.

Table 3. Crash cost calculated by road type and vehicle type (A $\$ / \mathrm{vkm})$ for Victoria $[\mathrm{AC}]$.

\begin{tabular}{cccc}
\hline Vehicle Type $(\mathrm{m})$ & Freeway & Highway & Other \\
\hline Car & 0.0088 & 0.0703 & 0.0703 \\
Short & 0.0064 & 0.0782 & 0.0412 \\
2 and 3 Axle Truck & 0.0076 & 0.0364 & 0.0260 \\
All Articulated Trucks & 0.0121 & 0.0800 & 0.0212 \\
\hline
\end{tabular}

\subsubsection{Infrastructure Costs}

Infrastructure costs (IC) can be broadly categorized into three elements. Namely, fixed costs, variable costs, and profits from infrastructure development (e.g. PPP Projects). Fixed costs (capital investment) can be shown as a cost per kilometer based on the number of lanes of the road which affect the capacity. Variable costs can be subdivided into two based on its nature of expenditure. First, as non-usage based fixed annual costs and secondly as, usage-based (variable) element. Finally, profits are determined based on market rates and the terms and conditions of the agreement made with the road authority. Since some road links are built under PPPs and other links are mainly funded through government budgets using the taxes of residents, capital cost investments, expected profit are quite subjective. Therefore, the IC calculated in this study is mainly looking at maintenance cost only for various infrastructure types caused by multi-class traffic.

Therefore, the cost of infrastructure $(\mathrm{A} \$ \mathrm{~km} / \mathrm{veh}$. type) can be considered simply as a function of a number of vehicles on that link for a unit of time (per year).

$$
I C_{a}^{m}=f\left(M_{a}^{m}, x_{a}^{m}\right) \quad \forall a \in A \bigcup \bar{A}, m \in M
$$


$M_{a}^{m}$ is taken from the literature (see Appendix B). The numbers given in Appendix B are cross-checked with the Australian (Victorian) real numbers and matched well. This cost can be calculated as:

$$
\sum_{a} \sum_{m} I C_{a}^{m} x_{a}^{m} d_{a} \quad \forall a \in A, m \in M
$$

\subsubsection{Emission Costs}

For this study emission costs generated by different vehicle types are calculated considering several harmful pollutants. Existing models and data were used to arrive at the final numbers and the process is briefly explained here. Fuel consumption for multi-class vehicles under different speeds and various emission components from fuel-burning were extracted from the [95].

Since the type of emission not only varies with vehicle type but also with vehicle age, an assumption was made to simplify the calculation complexity by considering all heavy vehicles were manufactured in years between 2003-2008, and for all light commercial vehicles, from years 2004 to 2005. In other words, a representative age was selected for each vehicle type. For simplicity, only the most significant and harmful emission types were considered, namely, carbon dioxide $\left(\mathrm{CO}_{2}\right)$, nitrogen oxide (NOx), sulfur oxide $\left(\mathrm{SO}_{\mathrm{x}}\right)$ and particulate matter (PM2.5).

To calculate the damage cost of each pollutant type, a damage cost model developed by the European Commission was used [96] [97]. In that model, the authors considered the health impacts on humans by toxic pollutants from road transportation and quantified the impacts in monetary terms. Impacts of GHG's were considered separately in terms of damage to buildings and materials, crop losses and biodiversity and ecosystems. The costs were converted to A (Australian Dollars) using the GDP ratio as instructed in the report. Therefore, emission costs can be written as a function of:

$$
E_{a}^{m}=f\left(e_{i}^{m}, e c_{i}, v_{a}, f^{m}(v), x_{a}^{m}\right)
$$

where

$e_{i}^{m}$-Different emission types ( $i$ ) given by weight (g or $\mathrm{kg}$ ) per vehicle type per liter of fuel consumed ( $\mathrm{g}$ or $\mathrm{kg} / \mathrm{one}$ liter of fuel);

$e c_{i}$-Cost by weight ( $\mathrm{g}$ or $\mathrm{kg}$ ) for different emission type (i) (A\$/g or $\left.\mathrm{kg}\right)$

$v_{a}$-Average speed on the link $a(\mathrm{~km} / \mathrm{hr})$;

$f^{m}(v)$ - Fuel consumption per kilometer travel by each vehicle class under given speed (liters);

$i=1$ for $\mathrm{CO}_{2}, i=2$ for PM2.5, $i=3$, for $\mathrm{NO}_{\mathrm{x}}$ and $i=4$ for $\mathrm{SO}_{\mathrm{x}}$.

Since the speed is classified into two sections, namely, free-flow conditions and stop-go conditions, there are two main scenarios in the emission cost calculation. After plotting all numbers in a chart, the following equation was extracted as a representative emission cost formula under different driving conditions. The coefficients and other relevant statistics are presented in Appendix C.

The total emission cost can be calculated as: 


$$
\begin{gathered}
\sum_{a} \sum_{m}\left[\left(a_{2} v_{a}^{2}+a_{1} v_{a}+a_{0}\right) \gamma+\left(c_{0}+\frac{c_{1}}{v_{a}}\right) \beta\right] x_{a}^{m} d_{a} \quad \forall a \in A \cup \bar{A}, m \in M \\
\text { if } 100 \geq v_{a} \geq 60, \gamma=1,0 \text { otherwise } \\
\text { if } 60>v_{a} \geq 10, \beta=1,0 \text { otherwise }
\end{gathered}
$$

where,

$a_{2}, a_{1}, a_{0}, c_{0}, c_{1}$ coefficients (values are given in Appendix $\mathrm{C}$ ).

Equation (7) denotes the emission costs as a function of its variables and Equation (8) denotes the final equations used to calculate emission costs under both free-flow and stop-go traffic conditions. The last two Equations (9) \& (10) denote the applicability of $\gamma$ and $\beta$ based on respective average link speed.

\subsubsection{Noise Costs}

Noise on roads refers to unwanted sounds and vibration from motor vehicles. Noise cost is a preliminary function of vehicle type, the number of vehicles, traffic flow condition (dense or thin), time of day and surrounding population density. To determine the traffic flow condition, the volume/capacity has been used in this study. For simplicity purposes, surrounding conditions are considered as urban only. The noise cost can be mathematically denoted as:

$$
N C_{a}^{m}=f\left(x_{a}^{m}, x_{a} / C_{a}, L_{t}\right) \quad \forall a \in A \bigcup \bar{A}, m \in M
$$

where,

$L_{t}$-time of day, $t=1$ for day and $t=2$ for night.

The total noise cost can be calculated as:

$$
\sum_{a} \sum_{m} N C_{a}^{m} x_{a}^{m} d_{a} \quad \forall a \in A, m \in M
$$

Equation (11) denotes the noise cost as a function of vehicle type, number of vehicles, v/c ratio and time of the day. Equation (12) represents the total noise cost calculated for given conditions. The coefficients required to calculate noise costs are given in Appendix D.

\subsubsection{Vehicle Operation Costs}

Vehicle operation cost estimates been published by authors elsewhere [87] and the following equation is used:

$$
\sum_{a} \sum_{m}\left(x_{a}^{m} d_{a} V C_{a}^{m}+x_{a}^{m} t_{a} V T^{m}\right) \quad \forall a \in A, m \in M
$$

Equation (13) denotes the vehicle operating costs formula that has been developed in previous studies. The VOC is not seeming to be so relevant here, but it is required when calculating appropriate toll charges when managing congestion and other traffic management related activities. Therefore, its presented in this paper for completeness.

\subsection{Model Objectives}

The intended objectives and benefits of a model are as follows. These objectives 
try to address multi-stakeholder problems and their objectives highlighted at the beginning of this paper and filling the gap for a new model.

- A comprehensive model that directly charge users for what they have consumed (no indirect charges based on supplementary products, transparent, maintains equity);

- No cross-subsidization of user costs;

- No subsidization of transport cost to other forms of revenue;

- Proper timely maintenance of the road network since required money is available;

- The real cost of transportation will be known to users (detailed, transparent calculation). This may help to shape the industry most efficiently;

- This leads to a more sustainable transport system in the future which encourages:

o Fuel efficient, safer fleets with high capacities;

o Optimum loading conditions leading to high load factors and efficiency (less unladen trips);

o Optimum routing, less pavement damage, less burden to society;

o Long term land use planning and control (Ex: location of warehouses, transhipment, etc.);

o Leads to more efficient logistics systems such as Urban Consolidation Centres and load pooling (vehicle sharing by different logistics providers);

o Mode shift from heavy freight vehicles to other sustainable transport modes such as rail or inland waterways if possible;

o Outsourcing transport services is another option where private hauliers usually suffer from less load factors;

o New industry practices such as JIT can be supported by re-structuring carrier's fleet based on different sizes of vehicles with less toll charge. However, increased frequency of travel, less mass transport leads to an increase in cost, but since the real cost of transportation is calculated it can be transferred to receivers and thus decisions will be made by receivers looking at marginal benefits.

Considering the above issues, there needs to be modelling methodology developed for determining the optimal level of road user charges for freight vehicles in urban areas that considers the objectives of key stakeholders as well as the social, environmental and economic impacts.

The model outlined needs to be capable of charging users directly for what they have truly consumed and this model promotes a more sustainable transportation system. However, the future of freight transportation should look at a more proactive manner shaping freight transport to its maximum possible way. In other words, the pricing structure should encourage users to move goods at its lowest possible cost, including externalities.

Charging users based on direct usage (including externalities) is not sufficient enough to create a sustainable transportation system where users behave independently. Thus, the authors suggest a pro-active method where RUC shall use 
as a tool to optimize the total cost of transportation. System optimized traffic assignment can be achieved if RUC is used as a tool to push users to such an optimum state. This will enable to minimize total travel cost while minimizing externalities.

Therefore, this will be a multi-objective optimization task considering multi-class of heavy vehicles, economic, social and environmental costs and benefit. Since these multi-objective are connected, conflicting sometimes, it is not easy to find a solution for such a condition. However, bi-level optimization techniques can be used in such circumstances where leaders followed by users and many researchers have used it to solve such transportation problems [98] [99] [100] [101].

\section{Conclusions}

Various road user charging mechanisms are adopted by different countries under various programs aiming at one or multiple objectives. A strong argument in the literature is that fuel taxation and registrations fees are imperfect tools to cover road user charges and more importantly the externalities. However, fuel taxes and registration fees still exist as a direct method to recover road user costs in many countries mostly due to political or public resistance. User demands have grown up for more usage-based charging systems and some countries have taken steps to achieve that fully or partially. Charging schemes developed and implemented have considered distance, emission, and pavement damage, and congestion factors, all or few, by some countries to a certain extent to cover direct impacts caused by HV, but still, there are gaps.

More rational methods of calculating road user charges are being hindered by technological, political and social acceptability in the phases of data collection method, implementation procedure followed by non-availability of models to calculate the damage caused to environment and society in the past. Moreover, the complexity of the solution holds the implementation of an ideal system on one end and political and social acceptability on the other end.

This paper has reviewed major existing road user charging mechanisms in the world, their key attributes, strengths and weaknesses. Subsequently, this paper has suggested a transparent, yet efficient, method for determining road user charges which incorporates the objectives of key stakeholders and the triple bottom line which can be used to improve the sustainability of urban freight transport in the future.

\section{Conflicts of Interest}

The authors declare no conflicts of interest regarding the publication of this paper.

\section{References}

[1] Conway, A. and Walton, C. (2009) Policy Options for Truck User Charging. Transportation Research Record: Journal of the Transportation Research Board, 2115, 75-83. https://doi.org/10.3141/2115-10 
[2] Fowkes, A.S., Nash, C.A. and Tweddle, G. (1992) Harmonizing Heavy Goods Vehicle Taxes in Europe: A British View. Transport Reviews, 12, 199-217. https://doi.org/10.1080/01441649208716816

[3] Gomez, J. and Vassallo, J.M. (2013) Comparative Analysis of Road Financing Approaches in Europe and the United States. Journal of Infrastructure Systems, 20, Article ID: 04014008. https://doi.org/10.1061/(ASCE)IS.1943-555X.0000193

[4] Lignier, P. (2011) The Role of Taxation in Addressing the Externalities of Road Transport: A Critical Analysis of Australian Tax Policy. Australian Tax Forum, 26, 137.

[5] McKinnon, A.C. (2006b) Government Plans for Lorry Road-User Charging in the UK: A Critique and an Alternative. Transport Policy, 13, 204-216.

https://doi.org/10.1016/j.tranpol.2005.09.002

[6] Newbery, D.M. and Santos, G. (1999) Road Taxes, Road User Charges and Earmarking. Fiscal Studies, 20, 103-132. https://doi.org/10.1111/j.1475-5890.1999.tb00006.x

[7] Parry, I.W.H. (2008) How Should Heavy-Duty Trucks Be Taxed? Journal of Urban Economics, 63, 651-668. https://doi.org/10.1016/j.jue.2007.04.007

[8] Winston, C. (1991) Efficient Transportation Infrastructure Policy. The Journal of Economic Perspectives, 5, 113-127. https://doi.org/10.1257/jep.5.1.113

[9] Forkenbrock, D.J. and Kuhl, J.G. (2002) A New Approach to Assessing Road User Charges. Transportation Policy Research, 14. https://doi.org/10.17077/71gx-vkt7

[10] Broaddus, A. and Gertz, C. (2008) Tolling Heavy Goods Vehicles: Overview of European Practice and Lessons from German Experience. Transportation Research Record: Journal of the Transportation Research Board, 2066, 106-113. https://doi.org/10.3141/2066-12

[11] Levinson, D. (2010) Equity Effects of Road Pricing: A Review. Transport Reviews, 30, 33-57. https://doi.org/10.1080/01441640903189304

[12] Downs, T.M. (2005) Is There a Future for the Federal Surface Transportation Program? Journal of Transportation Engineering, 131, 393-396. https://doi.org/10.1061/(ASCE)0733-947X(2005)131:6(393)

[13] Parry, I.W., Walls, M. and Harrington, W. (2007) Automobile Externalities and Policies. Journal of Economic Literature, 45, 373-399. https://doi.org/10.1257/jel.45.2.373

[14] Poole, R.W. (2007) The Case for Truck-Only Toll Lanes. Public Works Management \& Policy, 11, 244-249. https://doi.org/10.1177/1087724X07301599

[15] PwC (2013) Future Strategy for Road Supply and Charging.

[16] NTC Australia (2016a) Heavy Vehicle Charges-Options for Improving the Accuracy and Stability of the PAYGO Heavy Vehicle Charges Methodology.

[17] HVCI (2013) Heavy Vehicle Charging and Investment Options Development Discussion Paper.

[18] Oh, J.J. and Sinha, K.C. (2010) Self-Financing and Distance-Based Highway Pricing Scheme: State Highway System Perspective. Journal of Infrastructure Systems, 17, 95-106. https://doi.org/10.1061/(ASCE)IS.1943-555X.0000050

[19] Forkenbrock, D.J. (2005) Implementing a Mileage-Based Road User Charge. Public Works Management \& Policy, 10, 87-100. https://doi.org/10.1177/1087724X05283689

[20] Li, Z. and Hensher, D.A. (2010) Toll Roads in Australia: An Overview of Character- 
istics and Accuracy of Demand Forecasts. Transport Reviews, 30, 541-569. https://doi.org/10.1080/01441640903211173

[21] Chung, D., Hensher, D.A. and Rose, J.M. (2010) Toward the Betterment of Risk Allocation: Investigating Risk Perceptions of Australian Stakeholder Groups to Public-Private-Partnership Tollroad Projects. Research in Transportation Economics, 30, 43-58. https://doi.org/10.1016/j.retrec.2010.10.007

[22] Leccis, F. (2015) Public Private Partnerships for Transportation Infrastructure Delivery. Open Journal of Social Sciences, 3, 21-27. https://doi.org/10.4236/jss.2015.35004

[23] Odeck, J. and Bråthen, S. (2002) Toll Financing in Norway: The Success, the Failures and Perspectives for the Future. Transport Policy, 9, 253-260. https://doi.org/10.1016/S0967-070X(02)00030-6

[24] Goh, M. (2002) Congestion Management and Electronic Road Pricing in Singapore. Journal of Transport Geography, 10, 29-38. https://doi.org/10.1016/S0966-6923(01)00036-9

[25] Hau, T.D. (1990) Electronic Road Pricing: Developments in Hong Kong 1983-1989. Journal of Transport Economics and Policy, 24, 203-214.

[26] Albert, G. and Mahalel, D. (2006) Congestion Tolls and Parking Fees: A Comparison of the Potential Effect on Travel Behavior. Transport Policy, 13, 496-502. https://doi.org/10.1016/j.tranpol.2006.05.007

[27] de Palma, A., Kilani, M. and Lindsey, R. (2005) Congestion Pricing on a Road Network: A Study Using the Dynamic Equilibrium Simulator METROPOLIS. Transportation Research Part A: Policy and Practice, 39, 588-611. https://doi.org/10.1016/j.tra.2005.02.018

[28] Liu, L.N. and McDonald, J.E. (1998) Efficient Congestion Tolls in the Presence of Unpriced Congestion: A Peak and Off-Peak Simulation Model. Journal of Urban Economics, 44, 352-366. https://doi.org/10.1006/juec.1997.2073

[29] Wie, B.-W. (2007) Dynamic Stackelberg Equilibrium Congestion Pricing. Transportation Research Part C: Emerging Technologies, 15, 154-174. https://doi.org/10.1016/j.trc.2007.03.002

[30] Wie, B.-W. and Tobin, R.L. (1998) Dynamic Congestion Pricing Models for General Traffic Networks. Transportation Research Part B: Methodological, 32, 313-327. https://doi.org/10.1016/S0191-2615(97)00043-X

[31] Yang, H. and Huang, H.-J. (1997) Analysis of the Time-Varying Pricing of a Bottleneck with Elastic Demand Using Optimal Control Theory. Transportation Research Part B: Methodological, 31, 425-440. https://doi.org/10.1016/S0191-2615(97)00005-2

[32] Yang, H. and Meng, Q. (1998) Departure Time, Route Choice and Congestion Toll in a Queuing Network with Elastic Demand. Transportation Research Part B: Methodological, 32, 247-260. https://doi.org/10.1016/S0191-2615(97)00041-6

[33] Zhang, X. and Yang, H. (2004) The Optimal Cordon-Based Network Congestion Pricing Problem. Transportation Research Part B: Methodological, 38, 517-537. https://doi.org/10.1016/j.trb.2003.08.001

[34] Rotaris, L., Danielis, R., Marcucci, E. and Massiani, J. (2010) The Urban Road Pricing Scheme to Curb Pollution in Milan, Italy: Description, Impacts and Preliminary Cost-Benefit Analysis Assessment. Transportation Research Part A: Policy and Practice, 44, 359-375. https://doi.org/10.1016/j.tra.2010.03.008

[35] Gross, M. and Garvin, M. (2011) Structuring PPP Toll-Road Contracts to Achieve 
Public Pricing Objectives. Engineering Project Organization Journal, 1, 143-156. https://doi.org/10.1080/21573727.2011.572256

[36] Taniguchi, E. and Thompson, R.G. (2014) City Logistics: Mapping the Future. CRC Press, Boca Raton. https://doi.org/10.1201/b17715

[37] Taniguchi, E. and Thompson, R. (2002) Modeling City Logistics. Transportation Research Record: Journal of the Transportation Research Board, 1790, 45-51. https://doi.org/10.3141/1790-06

[38] Taniguchi, E., Thompson, R.G., Yamada, T. and van Duin, R. (2001) City Logistics: Network Modelling and Intelligent Transport Systems. Pergamon Press, Oxford. https://doi.org/10.1108/9780585473840

[39] European Comission (2010) Review of the Directive on Charging Heavy Goods Vehicles- "Eurovignette Directive"-Questions and Answers. http://europa.eu/rapid/press-release_MEMO-10-489_en.htm

[40] McKinnon, A.C. (2006) A Review of European Truck Tolling Schemes and Assessment of Their Possible Impact on Logistics Systems. International Journal of Logistics Research and Applications, 9, 191-205. https://doi.org/10.1080/13675560600859110

[41] Link, H. (2008) Acceptability of the German Charging Scheme for Heavy Goods Vehicles: Empirical Evidence from a Freight Company Survey. Transport Reviews, 28, 141-158. https://doi.org/10.1080/01441640701474809

[42] Dodoo, N.A. and Thorpe, N. (2005) A New Approach for Allocating Pavement Damage between Heavy Goods Vehicles for Road-User Charging. Transport Policy, 12, 419-430. https://doi.org/10.1016/j.tranpol.2005.06.009

[43] Gammelgaard, B., van Hoek, R. and Einbock, M. (2006) Effects of the Austrian Road Toll System on Companies. International Journal of Physical Distribution \& Logistics Management, 36, 153-169. https://doi.org/10.1108/09600030610656468

[44] Brown, K. (2007) Are Public-Private Transactions the Future of Infrastructure Finance? Public Works Management \& Policy, 12, 320-324. https://doi.org/10.1177/1087724X07303680

[45] Holguín-Veras, J., Cetin, M. and Xia, S. (2006) A Comparative Analysis of US Toll Policy. Transportation Research Part A: Policy and Practice, 40, 852-871. https://doi.org/10.1016/j.tra.2006.03.003

[46] Albalate, D. and Bel, G. (2009) What Local Policy Makers Should Know about Urban Road Charging: Lessons from Worldwide Experience. Public Administration Review, 69, 962-974. https://doi.org/10.1111/j.1540-6210.2009.02045.x

[47] Balducci, P.J. and Stowers, J. (2008) State Highway Cost Allocation Studies. National Cooperative Highway Research Program Synthesis Program, Washington DC. https://doi.org/10.17226/14178

[48] FHWA (1997) 1997 Federal Highway Cost Allocation Study Final Report. U.S. Department of Transportation. https://www.fhwa.dot.gov/policy/hcas/final/toc.cfm

[49] FHWA (2000) Addendum to the 1997 Federal Highway Cost Allocation Study Final Report. U.S. Department of Transportation. https://www.fhwa.dot.gov/policy/hcas/addendum.cfm

[50] National Transport Commission (NTC), Australia (2016) Heavy Vehicle Charges: Options for Improving the Accuracy and Stability of the PAYGO Heavy Vehicle Charges Methodology (Discussion Paper).

http://www.trb.org/Main/Blurbs/174489.aspx 
[51] Perera, L., Thompson, R.G. and Chen, Y. (2018) Understanding Road Freight Movements in Melbourne. In: Taniguchi, E. and Thompson, E., Eds., City Logistics 3, John Wiley \& Sons, Inc., Hoboken, 181-199. https://doi.org/10.1002/9781119425472.ch10

[52] Chen, Y., Perera, L. and Thompson, R.G. (2018) An Advanced Method to Provide Best Route Information in City Logistics with Toll Roads. Australasian Transport Research Forum 2018 Proceedings, Darwin, Australia, 10-11 April 2018, 16p.

[53] Perera, L., Thompson, R.G. and Yang, Y. (2016) Analysis of Toll Charges for Freight Vehicles in Melbourne. Australasian Transport Research Forum 2016, Melbourne, 16-18 November 2016, 16p.

[54] Lay, M.G. and Daley, K.F. (2002) The Melbourne City Link Project. Transport Policy, 9, 261-267. https://doi.org/10.1016/S0967-070X(02)00020-3

[55] Carey, A. and Willingham, R. (2017) Consumers Will Pay More When CityLink Truck Tolls Soar on April 1, Industry Warns. The Age. http://www.theage.com.au/victoria/consumers-will-pay-more-when-citylink-truck-t olls-soar-on-april-1-industry-warns-20170205-gu5tg4.html

[56] Thompson, R. (2014) Evaluating City Logistics Schemes. In: Taniguchi, E. and Thompson, R., Eds., City Logistics, CRC Press, Boca Raton, 101-114. https://doi.org/10.1201/b17715-8

[57] Thompson, R.G. and Hassall, K. (2006) A Methodology for Evaluating Urban Freight Projects. In: Recent Advances in City Logistics, Elsevier, Amsterdam, 283-291. https://doi.org/10.1016/B978-008044799-5/50106-6

[58] Poole, R.W. (1992) Introducing Congestion Pricing on a New Toll Road. Transportation, 19, 383-396. https://doi.org/10.1007/BF01098640

[59] Winslott-Hiselius, L., Brundell-Freij, K., Vagland, Å. and Byström, C. (2009) The Development of Public Attitudes towards the Stockholm Congestion Trial. Transportation Research Part A: Policy and Practice, 43, 269-282. https://doi.org/10.1016/j.tra.2008.09.006

[60] Jakobsson, C., Fujii, S. and Gärling, T. (2000) Determinants of Private Car Users' Acceptance of Road Pricing. Transport Policy, 7, 153-158. https://doi.org/10.1016/S0967-070X(00)00005-6

[61] De Borger, B. and Proost, S. (2012) A Political Economy Model of Road Pricing. Journal of Urban Economics, 71, 79-92. https://doi.org/10.1016/j.jue.2011.08.002

[62] Lave, C. (1994) The Demand Curve under Road Pricing and the Problem of Political Feasibility. Transportation Research Part A: Policy and Practice, 28, 83-91. https://doi.org/10.1016/0965-8564(94)90030-2

[63] Anas, A. and Lindsey, R. (2011) Reducing Urban Road Transportation Externalities: Road Pricing in Theory and in Practice. Review of Environmental Economics and Policy, 5, 66-88. https://doi.org/10.1093/reep/req019

[64] Kottenhoff, K. and Brundell Freij, K. (2009) The Role of Public Transport for Feasibility and Acceptability of Congestion Charging: The Case of Stockholm. Transportation Research Part A: Policy and Practice, 43, 297-305. https://doi.org/10.1016/j.tra.2008.09.004

[65] Ison, S. (1998) A Concept in the Right Place at the Wrong Time: Congestion Metering in the City of Cambridge. Transport Policy, 5, 139-146. https://doi.org/10.1016/S0967-070X(98)00017-1

[66] Ison, S. and Rye, T. (2005) Implementing Road User Charging: The Lessons Learnt from Hong Kong, Cambridge and Central London. Transport Reviews, 25, 451-465. https://doi.org/10.1080/0144164042000335788 
[67] Di Ciommo, F., Monzón, A. and Fernandez-Heredia, A. (2013) Improving the Analysis of Road Pricing Acceptability Surveys by Using Hybrid Models. Transportation Research Part A: Policy and Practice, 49, 302-316. https://doi.org/10.1016/j.tra.2013.01.007

[68] Ison, S. (2000) Local Authority and Academic Attitudes to Urban Road Pricing: A UK Perspective. Transport Policy, 7, 269-277. https://doi.org/10.1016/S0967-070X(00)00019-6

[69] Schade, J. and Baum, M. (2007) Reactance or Acceptance? Reactions towards the Introduction of Road Pricing. Transportation Research Part A: Policy and Practice, 41, 41-48. https://doi.org/10.1016/j.tra.2006.05.008

[70] Viegas, J.M. (2001) Making Urban Road Pricing Acceptable and Effective: Searching for Quality and Equity in Urban Mobility. Transport Policy, 8, 289-294. https://doi.org/10.1016/S0967-070X(01)00024-5

[71] Litman, T. (1996) Using Road Pricing Revenue: Economic Efficiency and Equity Considerations. Transportation Research Record: Journal of the Transportation Research Board, 1558, 24-28. https://doi.org/10.1177/0361198196155800104

[72] Zarrillo, M.L., Radwan, A.E. and Al-Deek, H.M. (1997) Modeling Traffic Operations at Electronic Toll Collection and Traffic Management Systems. Computers \& Industrial Engineering, 33, 857-860. https://doi.org/10.1016/S0360-8352(97)00266-0

[73] Hensher, D.A. and Puckett, S.M. (2007) Congestion and Variable User Charging as an Effective Travel Demand Management Instrument. Transportation Research Part A: Policy and Practice, 41, 615-626. https://doi.org/10.1016/j.tra.2006.07.002

[74] de Palma, A. and Lindsey, R. (2011) Traffic Congestion Pricing Methodologies and Technologies. Transportation Research Part C: Emerging Technologies, 19, 1377-1399. https://doi.org/10.1016/j.trc.2011.02.010

[75] Borins, S.F. (1988) Electronic Road Pricing: An Idea Whose Time May Never Come. Transportation Research Part A: General, 22, 37-44. https://doi.org/10.1016/0191-2607(88)90061-1

[76] Ogden, K.W. (2001) Privacy Issues in Electronic Toll Collection. Transportation Research Part C: Emerging Technologies, 9, 123-134. https://doi.org/10.1016/S0968-090X(00)00041-3

[77] Chen, C.-D., Fan, Y.-W. and Farn, C.-K. (2007) Predicting Electronic Toll Collection Service Adoption: An Integration of the Technology Acceptance Model and the Theory of Planned Behavior. Transportation Research Part C: Emerging Technologies, 15, 300-311. https://doi.org/10.1016/j.trc.2007.04.004

[78] Holguín-Veras, J. and Wang, Q. (2011) Behavioral Investigation on the Factors That Determine Adoption of an Electronic Toll Collection System: Freight Carriers. Transportation Research Part C: Emerging Technologies, 19, 593-605. https://doi.org/10.1016/j.trc.2010.09.010

[79] Jacob, B. and Feypell-de La Beaumelle, V. (2010) Improving Truck Safety: Potential of Weigh-in-Motion Technology. IATSS Research, 34, 9-15. https://doi.org/10.1016/j.iatssr.2010.06.003

[80] Sathaye, N., Horvath, A. and Madanat, S. (2010) Unintended Impacts of Increased Truck Loads on Pavement Supply-Chain Emissions. Transportation Research Part A: Policy and Practice, 44, 1-15. https://doi.org/10.1016/j.tra.2009.09.002

[81] Cebon, D. (1989) Vehicle-Generated Road Damage: A Review. Vehicle System Dynamics, 18, 107-150. https://doi.org/10.1080/00423118908968916

[82] Salama, H.K., Chatti, K. and Lyles, R.W. (2006) Effect of Heavy Multiple Axle Trucks 
on Flexible Pavement Damage Using In-Service Pavement Performance Data. Journal of Transportation Engineering, 132, 763-770. https://doi.org/10.1061/(ASCE)0733-947X(2006)132:10(763)

[83] Chou, C. (1996) Effect of Overloaded Heavy Vehicles on Pavement and Bridge Design. Transportation Research Record: Journal of the Transportation Research Board, 1539, 58-65. https://doi.org/10.1177/0361198196153900108

[84] Ren, J., Thompson, R.G. and Zhang, L. (2016) Investigating the Pavement Efficiency of Freight Vehicles Using Weigh-in-Motion Systems. 27 th ARRB Conference, Melbourne, 16-18 November 2016, 12p.

[85] Litman, T. (2009) Transportation Cost and Benefit Analysis. Victoria Transport Policy Institute, Victoria, 31.

https://www.researchgate.net/profile/Todd_Litman/publication/235360398_Transport ation_Cost_and_Benefit_Analysis_Techniques_Estimates_and_Implications/links/54 4a94ca0cf2d6347f401152.pdf

[86] Forkenbrock, D.J. (1999) External Costs of Intercity Truck Freight Transportation. Transportation Research Part A: Policy and Practice, 33, 505-526. https://doi.org/10.1016/S0965-8564(98)00068-8

[87] Yang, Y., Perera, L., Thompson, R. and Liu, Z. (2016) Determining Optimal Toll Levels for Trucks for City Logistics. 27 th ARRB Conference, Melbourne, 16-18 November $2016,17 \mathrm{p}$.

[88] Carey, A. (2017) Big Rise in CityLink Truck Tolls Tipped to Push Heavy Vehicles onto Local Roads. The Age.

http://www.theage.com.au/victoria/big-rise-in-citylink-truck-tolls-tipped-to-push-h eavy-vehicles-onto-local-roads-20170129-gu0vz3.html

[89] Atfield, C. (2017) Toll Rise to Bankroll Upgrade. The Age, 30.

[90] Albalate, D. and Bel, G. (2012) Motorways, Tolls and Road Safety: Evidence from Europe. SERIEs, 3, 457-473. https://doi.org/10.1007/s13209-011-0071-6

[91] Aljohani, K. and Thompson, R.G. (2016) Impacts of Logistics Sprawl on the Urban Environment and Logistics: Taxonomy and Review of Literature. Journal of Transport Geography, 57, 255-263. https://doi.org/10.1016/j.jtrangeo.2016.08.009

[92] HVCI (2013) Overview: Charging. http://www.ntc.gov.au/Media/Reports/(CB4BE14B-461C-47E2-AD20-5D36F3B5D8 BE).pdf

[93] Bereni, M. (2012) International Review of Road Funding and Heavy Vehicle Charging Mechanisms.

https://www.semanticscholar.org/paper/International-review-of-road-funding-andheavy-Bereni/6084c6c2f95b1b3d7f531f1d93470cc6548a7f82

[94] Tsekeris, T. and Voß, S. (2008) Design and Evaluation of Road Pricing: State-of-the-Art and Methodological Advances. NETNOMICS: Economic Research and Electronic Networking, 10, 5-52. https://doi.org/10.1007/s11066-008-9024-Z

[95] Transport and Infrastructure Council (2015) 2015 National Guidelines for Transport System Management in Australia-Road Parameter Values [PV2].

[96] Korzhenevych, A., Dehnen, N., Brocker, J., Holtkamp, M., Meier, H., Gibson, G., Varma, A. and Cox, V. (2014) Update of the Hand Book on External Costs of Transport (No. MOVE/D3/2011/571). European Commission DG Mobility and Transport.

[97] van Essen, H., Schroten, A., Otten, M., Sutter, D., Schreyer, C., Zandonella, R., Maibach, M. and Doll, C. (2011) External Costs of Transport in Europe-Update Study for 2008. CE Delft, INFRAS, Fraunhofer ISI. 
[98] Labbé, M. and Violin, A. (2013) Bilevel Programming and Price Setting Problems. 4OR, 11, 1-30. https://doi.org/10.1007/s10288-012-0213-0

[99] Li, H., Wang, D., Sun, X. and Yuan, Z. (2013) Using Bi-Level Multi-Objective Programming in Passenger Structure Optimization for Comprehensive Transportation Channel. Journal of Software, 8, 908-915.

[100] Tawfik, C. and Limbourg, S. (2015) Bilevel Optimization in the Context of Intermodal Pricing: State of Art. Transportation Research Procedia, 10, 634-643. https://doi.org/10.1016/j.trpro.2015.09.017

[101] Yamada, T., Russ, B.F., Castro, J. and Taniguchi, E. (2009) Designing Multimodal Freight Transport Networks: A Heuristic Approach and Applications. Transportation Science, 43, 129-143. https://doi.org/10.1287/trsc.1080.0250 


\section{Appendix}

Appendix A: Congestion Cost (A $\$ / \mathrm{vkm})$.

\begin{tabular}{|c|c|c|c|c|c|c|c|c|c|}
\hline \multirow{2}{*}{ Vehicle Type } & \multicolumn{3}{|c|}{ Free flow $(v / c<0.25)$} & \multicolumn{3}{|c|}{ Near capacity $(\mathrm{v} / \mathrm{c}<1)$} & \multicolumn{3}{|c|}{ Over capacity $(v / c>1)$} \\
\hline & Freeway & Highway & Other & Freeway & Highway & Other & Freeway & Highway & Other \\
\hline Cars and LCV & 0.00 & 0.016 & 0.043 & 0.465 & 2.450 & 2.766 & 1.066 & 3.144 & 4.207 \\
\hline Short & 0.00 & 0.016 & 0.043 & 0.465 & 2.450 & 2.766 & 1.066 & 3.144 & 4.207 \\
\hline 2 and 3 Axle Truck & 0.00 & 0.031 & 0.081 & 0.883 & 4.656 & 5.254 & 2.027 & 5.972 & 7.992 \\
\hline $\begin{array}{c}\text { Other } \\
\text { Articulated Truck }\end{array}$ & 0.00 & 0.047 & 0.125 & 1.346 & 7.106 & 8.020 & 3.093 & 9.114 & 12.199 \\
\hline
\end{tabular}

Source: [94].

Appendix B: Infrastructure Maintenance Cost (A $\$ / \mathrm{vkm})$.

\begin{tabular}{cccc}
\hline Vehicle Type & Freeway & Highway & Other \\
\hline Car & 0.003 & 0.005 & 0.014 \\
Short & 0.005 & 0.009 & 0.021 \\
2 Axle Truck & 0.028 & 0.047 & 0.373 \\
3 Axle Truck & 0.038 & 0.062 & 0.501 \\
4 Axle Articulated & 0.049 & 0.080 & 0.636 \\
5 Axle Articulated & 0.057 & 0.097 & 0.773 \\
6 Axle Articulated & 0.035 & 0.057 & 0.463 \\
B Double & 0.055 & 0.092 & 0.733 \\
Double Road Train & 0.075 & 0.125 & 1.001 \\
Triple Road Train & 0.137 & 0.227 & 1.821 \\
\hline
\end{tabular}

Source: [94].

Appendix C: Emission Cost Co-efficient.

\begin{tabular}{cccccc}
\hline \multirow{2}{*}{ Vehicle Type } & \multicolumn{3}{c}{$\begin{array}{c}\text { Free-Flow Condition } \\
(60-100 \mathrm{kmph})\end{array}$} & \multicolumn{2}{c}{$\begin{array}{c}\text { Stop-go condition } \\
(60-10 \mathrm{kmph})\end{array}$} \\
\cline { 2 - 6 } & $\mathrm{a}_{2}$ & $\mathrm{a}_{1}$ & $\mathrm{a}_{0}$ & $\mathrm{c}_{1}$ & $\mathrm{c}_{0}$ \\
\hline Car & $3.03 \mathrm{E}-06$ & -0.000297 & 0.0371 & 0.681 & 0.0334 \\
Short Vehicle & $7.43 \mathrm{E}-06$ & -0.000754 & 0.1017 & 2.104 & 0.0865 \\
2 Axle Truck & $1.32 \mathrm{E}-05$ & -0.000927 & 0.0895 & 1.215 & 0.1326 \\
3 Axle Truck & $3.45 \mathrm{E}-05$ & -0.00255 & 0.2765 & 4.618 & 0.3928 \\
4 Axle Articulated & $4.57 \mathrm{E}-05$ & -0.0031 & 0.3464 & 3.960 & 0.5520 \\
5 Axle Articulated & $4.23 \mathrm{E}-05$ & -0.0028 & 0.3659 & 4.378 & 0.5929 \\
6 Axle Articulated & $4.23 \mathrm{E}-05$ & -0.00273 & 0.3957 & 4.728 & 0.6508 \\
B Double & $4.32 \mathrm{E}-05$ & -0.0027 & 0.4911 & 5.626 & 0.8316 \\
Double Road Train & $4.40 \mathrm{E}-05$ & -0.0027 & 0.5619 & 6.246 & 0.9669 \\
Triple Road Train & $4.75 \mathrm{E}-05$ & -0.0027 & 0.7100 & 7.385 & 1.2576 \\
\hline
\end{tabular}


Appendix D: Cost of Noise in Urban areas under the different time of day and traffic condition $(\mathrm{A} \$ / \mathrm{km})$.

\begin{tabular}{ccccc}
\hline \multirow{2}{*}{ Vehicle Type } & \multicolumn{2}{c}{ Traffic Condition-Day } & \multicolumn{2}{c}{ Traffic Condition-Night } \\
\cline { 2 - 5 } & Dense & Thin & Dense & Thin \\
\hline Car & 0.0132 & 0.0321 & 0.02415 & 0.05835 \\
LCV & 0.066 & 0.1605 & 0.12045 & 0.29205 \\
All Articulated Trucks & 0.1215 & 0.2949 & 0.2217 & 0.5373
\end{tabular}

Source: [95]. 